\title{
Globin-like proteins in Caenorhabditis elegans: in vivo localization, ligand binding and structural properties
}

\author{
Eva Geuens ${ }^{\dagger 1}$, David Hoogewijs ${ }^{\dagger 2}$, Marco Nardini33, Evi Vinck4, Alessandra Pesce5 ${ }^{5}$ Laurent Kiger6, Angela Fago7, \\ Lesley Tilleman', Sasha De Henau8, Michael C Marden6, Roy E Weber7, Sabine Van Doorslaer ${ }^{4}$, Jacques Vanfleteren8, \\ Luc Moens ${ }^{1}$, Martino Bolognesi ${ }^{3}$ and Sylvia Dewilde*1
}

\begin{abstract}
Background: The genome of the nematode Caenorhabditis elegans contains more than 30 putative globin genes that all are transcribed. Although their translated amino acid sequences fit the globin fold, a variety of amino-acid substitutions and extensions generate a wide structural diversity among the putative globins. No information is available on the physicochemical properties and the in vivo expression.

Results: We expressed the globins in a bacterial system, characterized the purified proteins by optical and resonance Raman spectroscopy, measured the kinetics and equilibria of $\mathrm{O}_{2}$ binding and determined the crystal structure of GLB$1^{*}$ (CysGH2 T Ser mutant). Furthermore, we studied the expression patterns of glb-1 (ZK637.13) and glb-26 (T22C1.2) in the worms using green fluorescent protein technology and measured alterations of their transcript abundances under hypoxic conditions.GLB-1* displays the classical three-over-three a-helical sandwich of vertebrate globins, assembled in a homodimer associated through facing $\mathrm{E}$ - and F-helices. Within the heme pocket the dioxygen molecule is stabilized by a hydrogen bonded network including TyrB10 and GInE7.GLB-1 exhibits high ligand affinity, which is, however, lower than in other globins with the same distal TyrB10-GInE7 amino-acid pair. In the absence of external ligands, the heme ferrous iron of GLB-26 is strongly hexacoordinated with HisE7, which could explain its extremely low affinity for $\mathrm{CO}$. This globin oxidizes instantly to the ferric form in the presence of oxygen and is therefore incapable of reversible oxygen binding.
\end{abstract}

Conclusion: The presented data indicate that GLB-1 and GLB-26 belong to two functionally-different globin classes.

\section{Background}

The increasing availability of genomic data shows that globin-like proteins/domains $(\mathrm{Mr} \sim 17 \mathrm{kD})$ are universal and arose very early in the evolution of life [1]. Recent studies reveal new globin types as well as new functions (for a review see: [2-4]). A general survey suggests that the majority of nematodes host globin-like proteins [5]. Based on their tissue localisation, these proteins can be grouped in three classes: pseudocoelomic fluid, body wall, and cuticular hemoglobins $(\mathrm{Hb})$. Some nematode species may however lack a particular class [5]. To date,

*Correspondence: sylvia.dewilde@ua.ac.be

1 Department of Biomedical Sciences, University of Antwerp, Universiteitsplein

1, B-2610 Antwerp, Belgium

+ Contributed equally

Full list of author information is available at the end of the article the best characterized pseudocoelomic fluid $\mathrm{Hb}$ is the $\mathrm{Hb}$ from the ascarid Ascaris suum. This is an octameric molecule $(\mathrm{Mr} \sim 350 \mathrm{kDa})$ consisting of two layers of four subunits stacked in an eclipsed orientation [6]. Each subunit of $43 \mathrm{kDa}$ consists of two covalently linked, highly similar globin domains ( $\mathrm{Mr} \sim 17 \mathrm{kDa} ; 62 \%$ identical) followed by a C-terminal polar zipper of 23 amino acids. This $\mathrm{Hb}$ has an exceptionally high $\mathrm{O}_{2}$ affinity $\left(\mathrm{K}_{\mathrm{O} 2}=k_{\text {on }} / k_{\text {off: }} 0.215 \mathrm{M}^{-1}\right.$; $\mathrm{P}_{50}: 0.001-0.004$ torr at $20^{\circ} \mathrm{C}$ ) that is attributed to a very slow dissociation rate $\left(k_{\text {off }}\left(\mathrm{O}_{2}\right): 0.0041 \mathrm{~s}^{-1}\right)$ and a normal association rate $\left(k_{\text {on }}\left(\mathrm{O}_{2}\right): 1.5 \mu \mathrm{M}^{-1} \mathrm{~s}^{-1}\right)$ [6], whereby this $\mathrm{Hb}$ will be in the oxy form even in the host's gut with a locally micro-oxygen concentration [6]. This high $\mathrm{O}_{2}$ affinity can be explained structurally by the presence of 
three hydrogen bonds between TyrB10 and GlnE7 and the bound ligand $[7,8]$. The function of the A. suum pseudocoelomic fluid $\mathrm{Hb}$ is still a matter of debate (for a review see: $[5,6])$. Due to its extremely high $\mathrm{O}_{2}$ affinity, it will rarely be deoxygenated in vivo and cannot therefore function as an $\mathrm{O}_{2}$ carrier or store. Several alternative functions have been proposed, such as $\mathrm{O}_{2}$ or NO scavengers, iron and/or heme stores, catalyst in sterol biosynthesis, buffering, osmotic - or other unknown functions $[6,9]$.

The existence of globins in C. elegans was unexpected given the worm's small size, whereby sufficient amounts of $\mathrm{O}_{2}$ may reach the terminal oxidase sites by simple diffusion. The complete C. elegans genome revealed 33 globin-like genes, all having orthologues in the sibling species C. briggsae [10,11]. All 33 putative globin genes are expressed, albeit at low or very low levels, most likely indicating cell-specific expression. They show wide diversity in gene structure and amino-acid sequence of the translated proteins, suggesting a long evolutionary history. Nevertheless, sequence similarity to standard vertebrate globins, such as $\mathrm{Hb} \alpha, \beta$ chains, myoglobin $(\mathrm{Mb})$, neuro- and cyto-globin (Ngb and $\mathrm{Cygb}$ ) can be detected [11], despite the presence of additional interhelical, Nand/or C-terminal extensions. The intron/exon patterns of these C. elegans globin-coding genes are unique in the number of introns and in their insertion positions, compared to the highly conserved intron/exon pattern of vertebrate and other non-vertebrate globin genes (B12.2 and G7.0) $[11,12]$. Given the large number of $C$. elegans globin genes it is unlikely that they all serve simple $\mathrm{O}_{2}$ metabolism. C. elegans is a soil dwelling nematode; soil parameters such as temperature, moisture and $\mathrm{O}_{2}$ concentration fluctuate, creating temporary hypoxic/anoxic environments [13]. Living systems have developed, at the organism and cellular levels, various strategies to cope with reduced $\mathrm{O}_{2}$ levels, e.g. increasing the glycolytic flux, reducing the aerobic metabolic rate and increasing the efficiency of $\mathrm{O}_{2}$ uptake from the environment. However, nematodes including $C$. elegans lack both specialized respiratory systems and complex circulatory organs, and rely on respiratory adjustments at the molecular levels $[14,15]$.

Specialized $\mathrm{O}_{2}$-sensing cells in the nervous system of $C$. elegans permit rapid behavioural responses to $\mathrm{O}_{2}$ availability. The signal transduction pathway, detecting upper and lower $\mathrm{O}_{2}$ levels, involves the cGMP-gated channel $\operatorname{tax}-2 / \operatorname{tax}-4$ and a soluble guanylate cyclase homologue, $g c y$-35. The expressed N-terminal domain, GCY-35(1252) displays the spectral characteristics of a ferrous high-spin hemoprotein capable of $\mathrm{O}_{2}, \mathrm{CO}$ and $\mathrm{NO}$ binding [16]. Wild-type animals survive short periods of hypoxia/anoxia by greatly reducing metabolic rate and arresting movement and development. On the other hand the metabolic rate of the animals is not affected by increasing $\mathrm{O}_{2}$ levels up to $100 \%$ [17].

With the aim of shedding light on the roles played by $C$. elegans globins, we cloned several globin genes, and focussed our attention on two translation products (GLB1 and GLB-26). We analyzed their expression patterns and alterations of transcript abundance under hypoxia. We then analyzed the two expressed globins through optical and resonance Raman spectroscopy, characterized the kinetics of ligand binding and $\mathrm{O}_{2}$ equilibrium properties, and determined the high resolution crystal structure of GLB-1. The results are discussed in the context of current views on multivariate globin function, of heme/ligand recognition mechanisms, and of the evolution of the globin fold through the phyla.

\section{Results}

\section{Expression cloning of globins}

Eight $C$. elegans globins were selected for cloning and expression. These were the canonical globin, GLB-1, three globins (GLB-14, GLB-18, GLB-29) that show sequence similarity to Cygb, two globins displaying similarity to Ngb (GLB-7, GLB-13), GLB-23 that contains an exceptionally large N-terminal extension, and GLB-26 in which Ile substitutes the highly conserved Phe at position CD1. All globin genes were cloned into pET3a and expressed in vitro in E. coli. After expression, only two globins, GLB-1 and GLB-26 were found in the cytosolic fractions with incorporated heme, whereas all the others were present as apo-proteins in inclusion bodies. All attempts to reconstruct the purified apo-proteins with hemin in vitro using different methods (see Methods and additional file 1 Table S1 and Figure S1) failed. As many globins are easily reconstructed from hemin and their apo-protein we concluded that GLB-7, GLB-13, GLB-14, GLB-18, GLB-23 and GLB-29 under the conditions used are unable to bind heme and/or properly fold into a native hemoprotein.

Based on previous experience with different globins, for crystallisation purposes, the Cys residues in GLB-1 were mutated to Ser. In GLB-1 Cys residues are present at positions A11, E15 and GH2. Mutation of CysA11 and/or CysE15 to Ser resulted in expression in inclusion bodies and in failure to incorporate hemin in vitro under the conditions used. In contrast, mutation of CysGH2 into Ser (GLB-1*) resulted in expression in the cytosolic fraction as a heme-containing globin. Inspection of the 3D structure of GLB-1* (see below) shows that the Cys residues at positions A11 and E15 are $9 \AA$ apart and not linked by a disulphide bridge. The intrinsic incorrect folding displayed by the A11 and E15 Ser mutants sug- 
gests that the formation of a temporary disulfide bridge between these two residues is necessary during folding of the protein.

Gel filtration chromatography on a calibrated Superdex $^{\text {mi }} 75$ column equilibrated in $50 \mathrm{mM}$ Tris- $\mathrm{HCl} \mathrm{pH} \mathrm{8.5,}$ $150 \mathrm{mM} \mathrm{NaCl}$ and $0.5 \mathrm{mM}$ EDTA clearly shows that GLB-1, GLB-1* and GLB-26 behave in solution as non covalently bound dimers (data not shown).

\section{UV/VIS and Resonance Raman spectra}

UV/VIS absorbance spectra of GLB-1 (as purified) shows the Soret band centered at $414 \mathrm{~nm}$ (Figure 1A); the $\beta$ - and $\alpha$ - peaks at $\sim 542$ and $\sim 580 \mathrm{~nm}$, respectively, typical of an oxygenated globin. The shoulder at $635 \mathrm{~nm}$ indicates that a considerable fraction of a high-spin (HS) ferric species is also present. After deoxygenation and reduction, the Soret band shifts to $430 \mathrm{~nm}$ and the visible absorbance spectrum changes to that typical for the pentacoordinated HS ferrous form of globins. In the absorption spectrum of CO-ligated ferrous GLB-1, the Soret band peak at $\sim 421 \mathrm{~nm}$, and the $\beta$ - and $\alpha$-bands at $\sim 540$ and $\sim 572 \mathrm{~nm}$, respectively. The UV/VIS spectra of GLB-1* match those of w.t. GLB-1 (not shown).

The high-frequency region of the RR spectrum of GLB1 (as purified) is in agreement with the UV/VIS spectrum indicating a prevalence of the oxy form $\left(v_{4}, v_{3}\right.$, and $v_{2}$ situated at $\sim 1375 \mathrm{~cm}^{-1}, \sim 1505 \mathrm{~cm}^{-1}$, and $\sim 1580 \mathrm{~cm}^{-1}$ respectively) (Figure $2 \mathrm{~B}(\mathrm{a})$ ). The weak line at $1470 \mathrm{~cm}^{-1}$ indicates a small HS ferric fraction, in agreement with the UV/VIS spectra. After deoxygenation and reduction, the RR spectrum becomes typical of a (pentacoordinated) HS ferrous globin, again paralleling the UV/VIS data $\left(v_{4}\right.$, and $v_{3}$ at $\sim 1355 \mathrm{~cm}^{-1}$, and $\sim 1470 \mathrm{~cm}^{-1}$ respectively (Figure $2 \mathrm{~B}(\mathrm{~b})$ ).
Furthermore, the $v(\mathrm{Fe}-\mathrm{His})$ stretching mode is observed at $225 \mathrm{~cm}^{-1}$, typical for HS globins (Figure 2A(b)). The RR spectra of GLB-1* matched closely those of GLB-1 (data not shown).

The RR spectrum of the CO-ligated form of GLB-1 displays $v_{4}, v_{3}$, and $v_{2}$ at $\sim 1375 \mathrm{~cm}^{-1}, \sim 1505 \mathrm{~cm}^{-1}$, and $\sim 1585$ $\mathrm{cm}^{-1}$ respectively (Figure $2 \mathrm{~B}(\mathrm{c})$ ). Upon increase of the laser power, a second component appears in the RR spectrum (Figure $2 \mathrm{~B}(\mathrm{~d}))$. This component $\left(v_{4} \sim 1356 \mathrm{~cm}^{-1}\right.$ and $\left.v_{3} \sim 1470 \mathrm{~cm}^{-1}\right)$ is typical of HS ferrous globins, indicating that photodissociation of $\mathrm{CO}$ has taken place. A strong peak around $\sim 493 \mathrm{~cm}^{-1}$ is observed that decreases upon strong photo-dissociation (not shown), indicative of the $v(\mathrm{Fe}-\mathrm{CO})$ mode (Figure $2 \mathrm{~A}(\mathrm{c}-\mathrm{d})$ ). Fe-CO stretching modes at higher frequencies cannot be observed. However, it should be noted that, since no isotopic labelling of the $\mathrm{CO}$ ligand was performed, weak $\mathrm{Fe}-\mathrm{CO}$ stretching modes may escape attention and the current results should be interpreted cautiously.

The Soret band of GLB-26 (as purified) is found at 413 $\mathrm{nm}$ (Figure 1B), and the $\beta$ - and $\alpha$-bands display maxima at 530 and $565 \mathrm{~nm}$, respectively, indicating that the globin is in a hexacoordinated low-spin (LS) ferric state. Upon reduction, the Soret band shifts to $424 \mathrm{~nm}$, indicative of ferrous globins, with an intense $\alpha$ band at $560 \mathrm{~nm}$ indicating a hexacoordinated LS ferrous heme protein. The COligated ferrous GLB-26 exhibits a typical UV/VIS spectrum, as also observed for CO-ligated GLB-1.

The RR spectra of GLB-26 (as purified) are typical of hexacoordinated LS ferric heme proteins $\left(v_{4}, v_{3}\right.$, and $v_{2}$ at $\sim 1375 \mathrm{~cm}^{-1}, \sim 1505 \mathrm{~cm}^{-1}$, and $\sim 1580 \mathrm{~cm}^{-1}$, respectively), in agreement with the UV/VIS data (Figure 2D(a)). In the
(A)

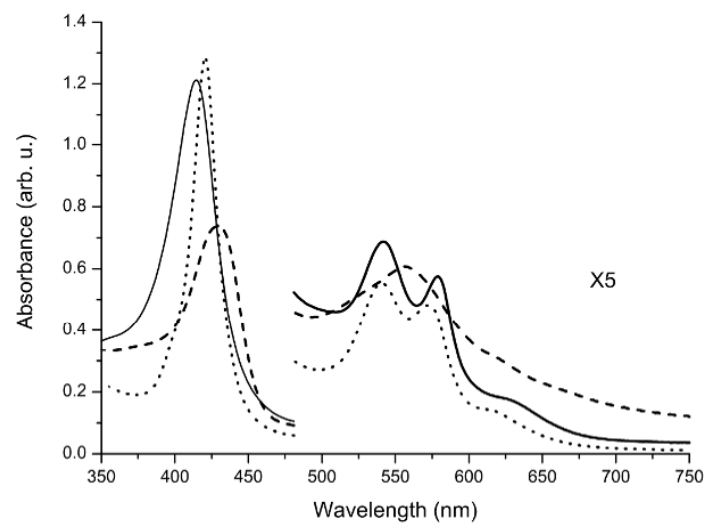

(B)

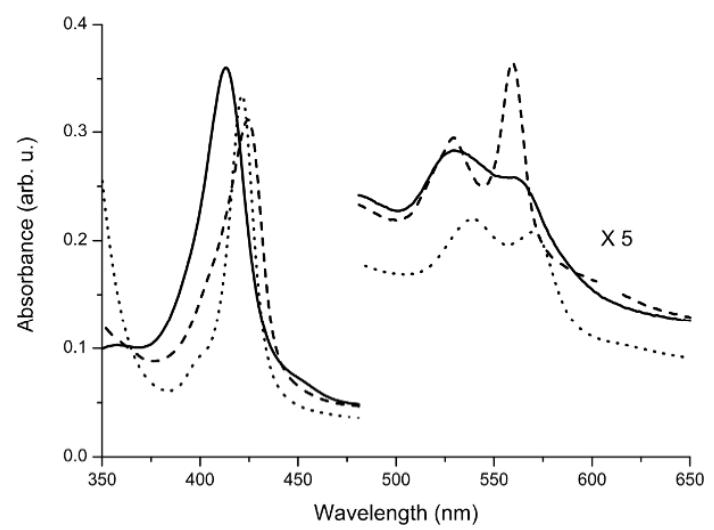

Figure 1 UV/VIS spectra of different forms of (A) GLB-1 and (B) GLB-26. Solid line: as-purified protein; dashed line: deoxy ferrous form; dotted line: CO-ligated ferrous form. 
(A)

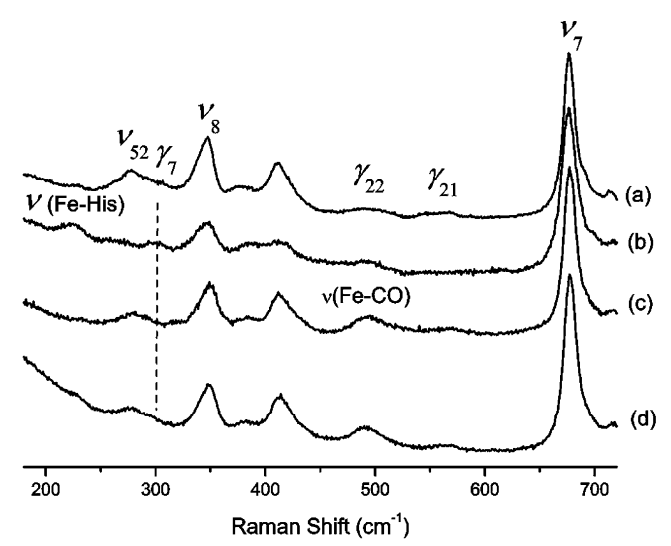

(C)

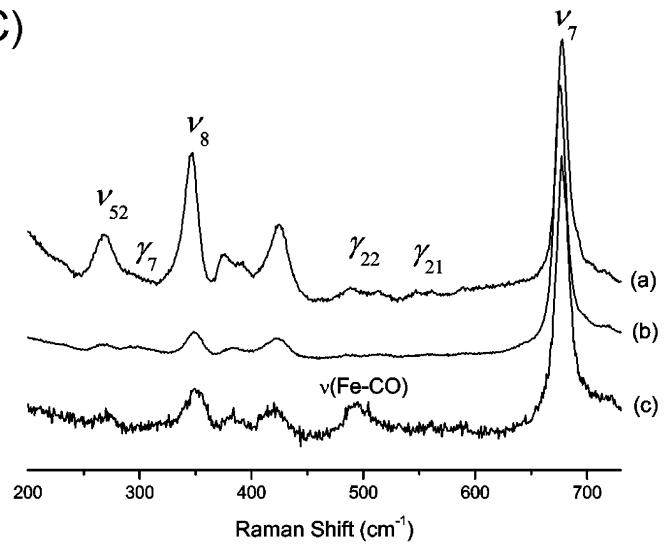

(B)

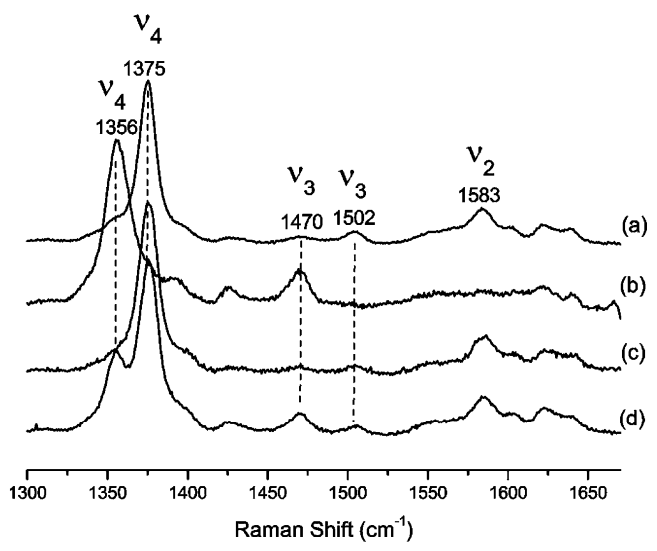

(D)

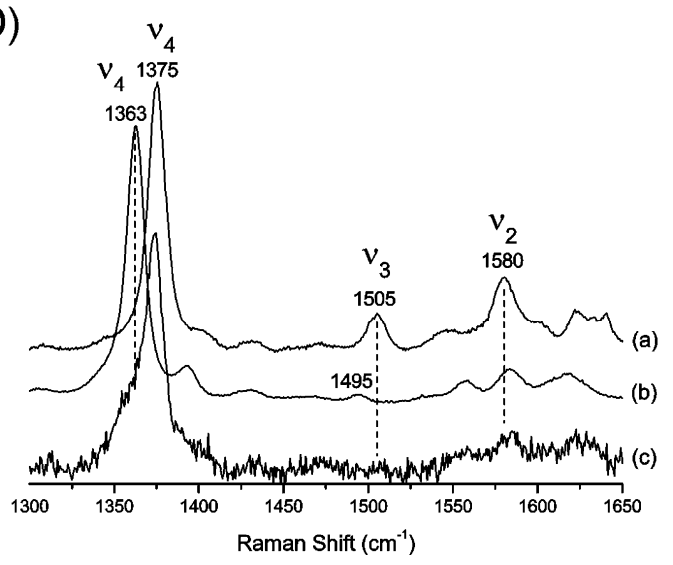

Figure 2 RR spectra of GLB-1 and GLB-26. (A) Low-frequency region and (B) high-frequency region (GLB-1) (a) As-purified form, laser power $30 \mathrm{~mW}$ (b) deoxy ferrous form, laser power $50 \mathrm{~mW}$ (c) CO form, laser power $2 \mathrm{~mW}$, (d) CO form, laser power $40 \mathrm{~mW}$. (C) Low-frequency region and (D) highfrequency region (GLB-26) (a), As-purified form, laser power $20 \mathrm{~mW}$ (b) deoxy ferrous form, laser power $25 \mathrm{~mW}$ (c) CO form, laser power $1 \mathrm{~mW}$.

low-frequency region, the out-of-plane mode $\gamma_{7}$ is hardly detectable, indicating no significant out-of-plane distortion (Figure $2 \mathrm{C}(\mathrm{a})$ ). After reduction of GLB-26, the RR spectra become typical for hexacoordinated LS ferrous globins ( $v_{4}$ and $v_{3}$, at $\sim 1364 \mathrm{~cm}^{-1}$ and $\sim 1495 \mathrm{~cm}^{-1}$, respectively) (Figure $2 \mathrm{D}(\mathrm{b})$ ). In the RR spectrum of the COligated ferrous form of GLB-26, the $v(\mathrm{Fe}-\mathrm{CO})$ mode is again situated at $\sim 493 \mathrm{~cm}^{-1}$ (Figure $2 \mathrm{C}(\mathrm{c})$ ). No clear $v(\mathrm{Fe}-$ $\mathrm{CO})$ modes were observed at higher frequencies.

\section{The 3D structural model of GLB-1*}

The structure of GLB-1* (bearing the Cys(127)GH2 T Ser mutation to avoid protein aggregates during crystallization) was solved by MAD methods based on the anomalous signal of the heme iron atom. Diffraction data were collected at three wavelengths at the ID29 ESRF beamline (Grenoble, France), for the tetragonal $P 4_{3} 2_{1} 2$ form (one
GLB-1* molecule per asymmetric unit). Refinement of the crystal structure (at $1.5 \AA$ resolution) converged at a general $R_{\text {factor }}$ value of $16.3 \%$ ( $R_{\text {free }}$ of $20.1 \%$ ), with ideal stereochemical parameters $[18,19]$. The final model contains 1,305 protein atoms (residues 2-159), 1 heme, 1 dioxygen molecule and 202 ordered solvent atoms ( 2 of them in alternate sites) (for details see additional file 2 Table S2). The tertiary structure of GLB-1* conforms to the three-over-three $\alpha$-helical sandwich of the classical globin fold [20,21], where the seven/eight helices building up the globin fold are conventionally labelled, A, B, ..., H, according to their sequential order (topological sites are numbered sequentially within each helix; [22]). For comparison, a rmsd value of $1.79 \AA$ is calculated (over $125 \mathrm{C} \alpha$ atom pairs) in a structural overlay on sperm whale $\mathrm{Mb}$, the largest structural deviation matching a 4-residue insertion at the $\mathrm{AB}$ loop, the $\mathrm{CD}$ interhelical region (one- 
residue insertion), a 3-residue insertion at the EF hinge, and a 2-residue deletion in the GH region. Residues 17-19 (the last turn of the A-helix), 43-48 (the C-helix) and 102104 (the last turn of the F-helix) of GLB-1* display a $33_{10}$ conformation.

The diffraction data collected at $2.8 \AA$ resolution on GLB- $1 *$ crystals grown in the trigonal $P 3_{1} 21$ space group (two molecules per asymmetric unit) were also refined, yielding $\mathrm{R}_{\text {factor }}$ and $\mathrm{R}_{\text {free }}$ values of $26.9 \%$ and $31.9 \%$, respectively, with ideal stereochemical parameters (for details additional file 2 Table S2). Superposition of $158 \mathrm{C}_{\alpha}$ atoms of the two independent molecules, in the trigonal crystal form, yielded a rmsd of $0.53 \AA$. Comparison of the GLB$1^{*}$ structures from the tetragonal and trigonal crystal forms yielded rmsd of $0.53 \AA$ and $0.42 \AA$, for $158 \mathrm{C}_{\alpha}$ atoms, depending on the chains superposed. The only backbone differences observed in the two crystal forms are located at the $\mathrm{N}$ - and $\mathrm{C}$-terminal residues of the polypeptide chain (residues 2 and 159, respectively), and at residues 124-126 of the $\mathrm{GH}$ hinge.

All results discussed below apply to both tetragonal and trigonal crystal forms unless otherwise stated. In the high resolution tetragonal crystal form the crystallographic two-fold axis gives rise to a GLB-1* homodimer, whose $945 \AA^{2}$ association interface is mostly built by residues belonging to the E- and F helices (residues 72-83, and 87101 respectively), and to the $A B$ (residues 20-25) and $E F$ (residues 84-86) corners of both chains. The crystallographic dimer is identical to the quaternary assembly found in the trigonal crystal form, where two crystallographically independent GLB-1* chains fill the asymmetric unit. The rmsd calculated over the whole dimer in the two crystal forms is $0.50 \AA$. The heme groups belonging to the two subunits lie $21 \AA$ far apart (Fe to Fe distance). In particular, the D-propionates of each heme group are stabilized by an intramolecular salt bridge with the $\mathrm{NH}_{2}$ of residue $\operatorname{Arg}(100) \mathrm{F} 7(2,77 \AA)$, and can establish an intermolecular salt bridge with $\operatorname{Arg}(100) F 7^{\prime}$ belonging to the facing subunit $(4,1 \AA$; Figure 3$)$. The dimerization interface observed for the GLB-1 dimer is tightly packed, the stability of the assembly being granted by several hydrophobic interactions, hydrogen bonds (also mediated by water molecules and, in the trigonal crystal form, also by sulphate ions) and salt bridges. Such a highly symmetrical homodimer (all intermolecular interactions obey a 2-fold symmetry) is predicted to be energetically stable by the Protein Interfaces, Surfaces and Assemblies (PISA) detection software [23]. Remarkably, the GLB-1* dimeric assembly is strictly reminiscent of the quaternary assembly observed in Scapharca inaequivalvis $\mathrm{Hb}$ [24] and in Caudina arenicola $\mathrm{Hb}$ [25].

Stabilization of the heme group within the GLB- $1 *$ fold occurs through 95 van der Waals contacts $(\leq 4.0 \AA)$; moreover, salt links are present between residue Arg(65)E3 and heme A-propionate, and between residue Arg(100)F7 and heme D-propionate. These two Arg residues, together with $\operatorname{Arg}(72) \mathrm{E} 10$, Lys(50)C7, Lys(68)E6, and Lys(105) build an evident positively charged patch around the heme crevice, mostly located on the heme distal side (Figure 4). The proximal His(101)F8 residue is properly coordinated to the heme-Fe atom (2.06 $\AA$ coordination bond), and is fully staggered relative to the porphyrin pyrrole $\mathrm{N}$-atoms, allowing in principle a short Fe-HisF8 coordination bond, and in-plane location of the Fe atom. The HisF8 staggered orientation is defined by a strong hydrogen bond (2.83 $\mathrm{A}$ ) of His(101)F8 ND1 atom to the carbonyl $\mathrm{O}$ atom of residue $\mathrm{Thr}(97) \mathrm{F} 4$.

Thanks to the high stability of the oxygenated form, the distal site of the crystallized GLB-1 hosts an $\mathrm{O}_{2}$ molecule coordinated to the heme-Fe atom (Fe --- O1 coordination distance $2.12 \AA$ ), adopting a moderately bent geometry (the $\mathrm{Fe}-\mathrm{O} 1-\mathrm{O} 2$ angle is $155^{\circ} \mathrm{C}$. The dioxygen molecule is stabilized, by a direct hydrogen bond (3.01 $\AA$ ) to $\operatorname{Tyr}(35) \mathrm{B} 10$, that in turn is hydrogen bonded (2.85 $\AA$ ) to the NE2 atom of Gln(69)E7 (Figure 4). Tyr(35)B10 and $\mathrm{Gln}(69) \mathrm{E} 7$ are the only polar residues in the heme distal site, which is essentially lined by aromatic residues (Phe(34)B7, Phe(38)B11, Phe(49)C6, Phe(66)E4, Ile(73)E11, and Phe(114)G8). Likely related to the overall apolarity, but also to the steric constraints posed by the above mentioned residues, no water molecules are observed in the heme distal site. The GLB-1* heme distal site resembles that of $A$. suum $\mathrm{Hb}$, with TyrB10 directly stabilizing the $\mathrm{O}_{2}$ molecule and GlnE7 making a hydrogen bond with the $\mathrm{B} 10$ residue [7]. In A. suum $\mathrm{Hb}$ the coordination bond Fe---O1 is shorter $(1.90 \AA)$ than that found in $\mathrm{GLB}-1^{*}$ and, due to the Arg T Phe residue substitution at the E3 topological site, the GLB-1* salt bridge to the heme A-propionate is not present in A. suum $\mathrm{Hb}$.

\section{Ligand-binding: kinetic measurements and equilibrium data}

The ligand-binding characteristics for both globins were measured using flash photolysis (Table 1). For GLB-1, the CO-rebinding kinetics are monophasic (Figure 5) and the $\mathrm{k}_{\text {off }}$ for $\mathrm{O}_{2}$ is two orders of magnitude lower than for $\mathrm{Mb}$, resulting in a high $\mathrm{O}_{2}$ affinity $\left(46 \mu \mathrm{M}^{-1}\right.$, Table 1$)$. Accordingly, $\mathrm{O}_{2}$-equilibrium experiments show that the $\mathrm{O}_{2}$ affinity of GLB-1 is high and $\mathrm{pH}$-independent (Table 1, Figure 6), with $P_{50}$ values of $0.062 \pm 0.023$ and $0.047 \pm 0.007$ torr at $\mathrm{pH} 6.90$ and 7.54, respectively. Hill coefficients below unity (0.75 and 0.61 at $\mathrm{pH} 6.90$ and 7.54, respectively) indicate that the subunits of this dimeric globin have different $\mathrm{O}_{2}$ affinity (here functional heterogeneity seems to apply only to $\mathrm{O}_{2}$ binding as $\mathrm{CO}$ kinetics are monophasic). 

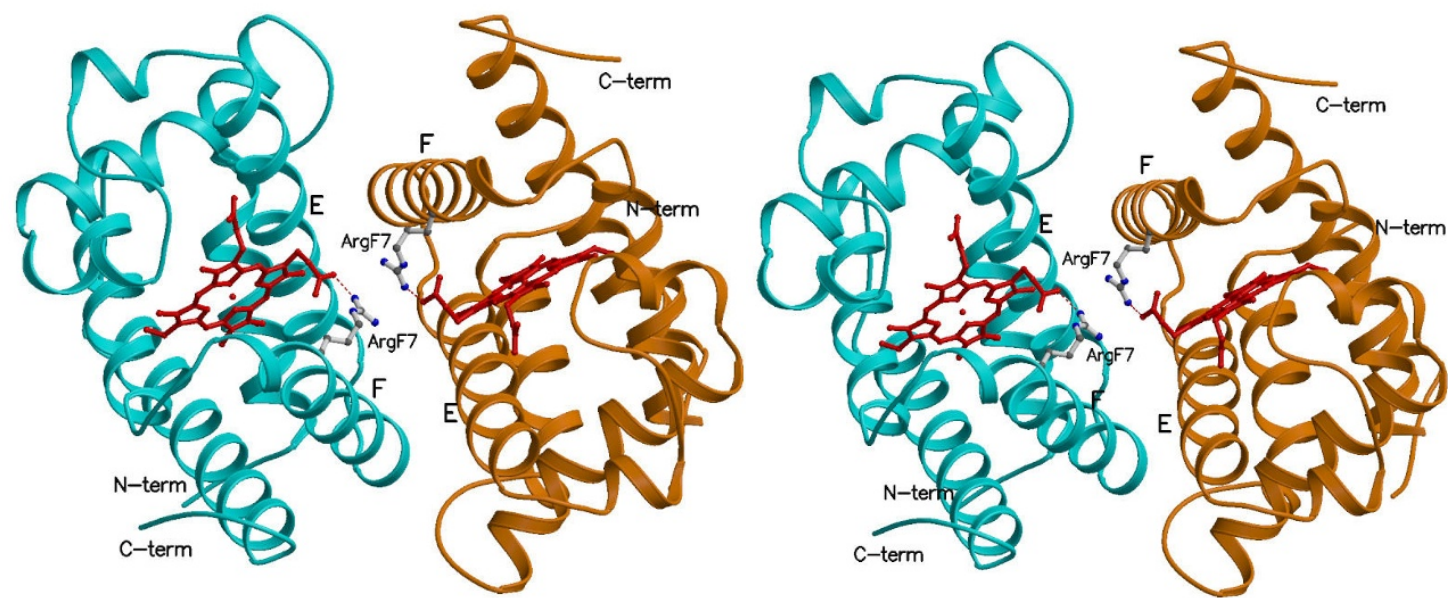

Figure 3 The GLB-1* dimeric assembly. A stereo view of the GLB-1* dimer. The two GLB-1* subunits, interacting mainly through the E and $F$ helices, are shown in cyan and orange ribbon models. In GLB-1*P4 $2_{3} 2$ form the dimer sits on a crystallographic 2 -fold axis, whereas in the $P 3_{1} 21$ form one dimer is present in the crystallographic asymmetric unit. Figure drawn with Molscript [66].

The same experiments were performed for GLB-26. It was difficult to measure the kinetics of GLB-26, because this globin is readily oxidized to the ferric species in the presence of O2. Several reducing systems were tried, but even then it was not possible to keep the heme iron of this protein reduced in the presence of O2. However, GLB-26 is easily reduced anaerobically by sodium dithionite or by NADPH under light exposure.
The CO-rebinding kinetics to the hexacoordinated GLB-26 are characterized by a biphasic trace (Figure 5) with a slow phase of replacement due to the slow dissociation of the distal residue. The characterization of this slow phase was confirmed by measurement of the full absorption spectra versus time (Figure 7). Based on the $\mathrm{k}_{\text {on }}$ for the CO ligand, the $\mathrm{k}_{\text {on }}$-value for the distal ligand His was calculated to be $20000 \mathrm{~s}^{-1}$.
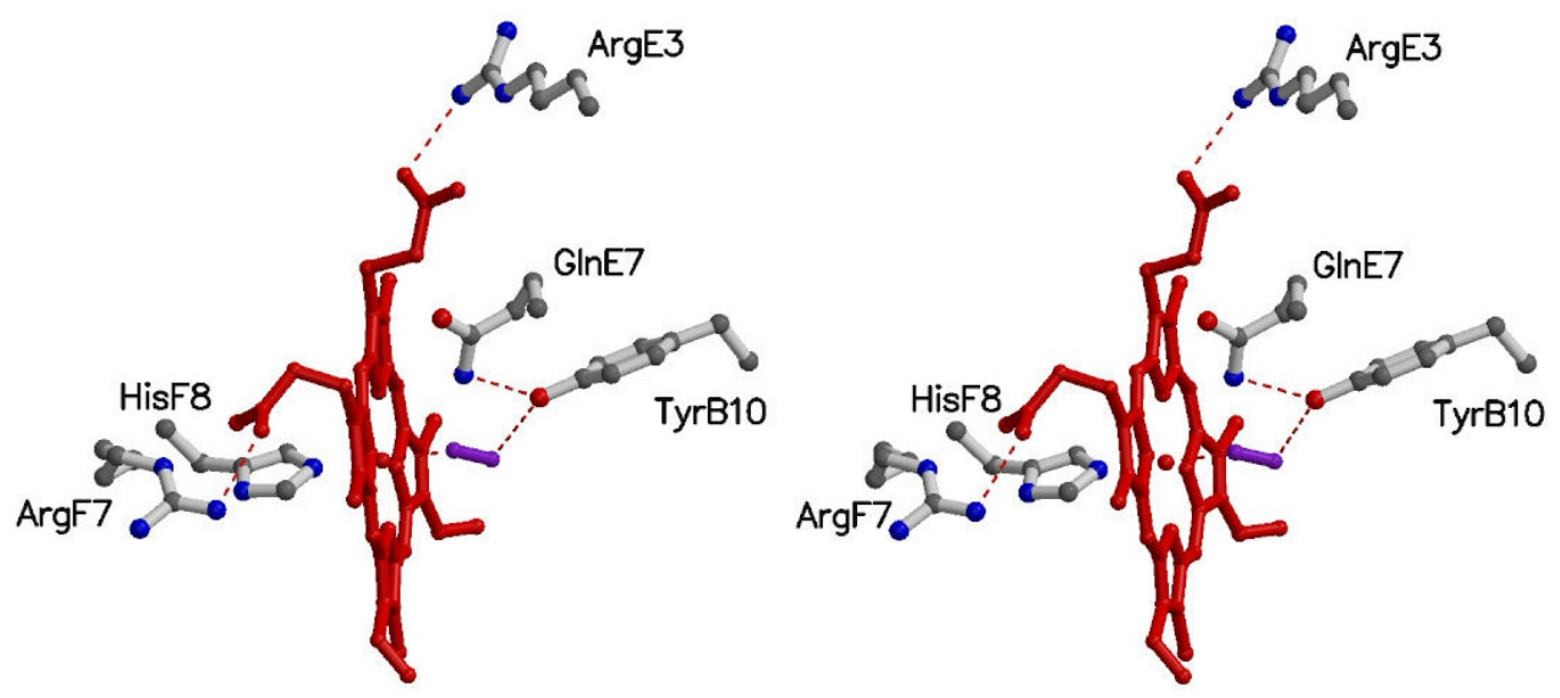

Figure 4 The heme site pocket of GLB-1*. Stereo view of the heme, of the proximal His(101)F8, of the distal Gln(69)E7 and of the surrounding residues contacting the heme. The $\mathrm{O}_{2}$ molecule is shown in ball-and-stick (violet). When appropriate, residue topological positions are indicated. Hydrogen bonds are dashed. Figure drawn with Molscript [66] (For the electron density maps see additional file 2, figure S2). 
Table 1: Rates of ligand binding of $C$. elegans globins compared to rates reported for other globins.

\begin{tabular}{|c|c|c|c|c|c|c|}
\hline & & $\begin{array}{c}\text { C.elegans } \\
\text { GLB-1 }\end{array}$ & $\begin{array}{l}\text { C.elegans } \\
\text { GLB-26 }\end{array}$ & $\begin{array}{c}\text { H.sapiens } \\
\text { NGB }\end{array}$ & $\begin{array}{l}\text { Sperm whale } \\
\text { Mb }\end{array}$ & $\begin{array}{c}\text { A.suum } \\
\mathrm{Hb}\end{array}$ \\
\hline \multirow[t]{8}{*}{02} & kon & 23 & n.d. & 250 & 14 & 3 \\
\hline & $\mu \mathrm{M}-1 \mathrm{~s}-1$ & & & & & \\
\hline & koff & 0.5 & n.d & 0.8 & 12 & 0.013 \\
\hline & $s-1$ & & & & & \\
\hline & $K=$ kon $/$ koff & 46 & n.d & 313 & 1.1 & 215 \\
\hline & $\mu \mathrm{M}-1$ & & & & & \\
\hline & P50 & 0.003 & n.d & 1 & 1 & 0.0072 \\
\hline & torr & & & & & \\
\hline \multirow[t]{5}{*}{ His } & kon & - & 20000 & - & - & - \\
\hline & $s-1$ & & & & & \\
\hline & koff & - & 0.3 & - & - & - \\
\hline & $s-1$ & & & & & \\
\hline & $K=$ kon $/$ koff & - & 66667 & - & - & - \\
\hline \multirow[t]{6}{*}{ CO } & kon & - & 23 & 65 & 0.5 & 0.21 \\
\hline & $\mu \mathrm{M}-1 \mathrm{~s}-1$ & & & & & \\
\hline & koff & - & 0.05 & 0.01 & 0.02 & 0.018 \\
\hline & $s-1$ & & & & & \\
\hline & $K=$ kon $/$ koff & - & 460 & 4643 & 28 & 12 \\
\hline & $\mu M-1$ & & & & & \\
\hline
\end{tabular}

(values for $\mathrm{H}$. sapiens $\mathrm{Ngb}$ and sperm whale $\mathrm{Mb}$ from ref [67] and for A. suum $\mathrm{Hb}$ from ref [68])

n.d.: not detectable

Note: $\left.\mathrm{K}_{\mathrm{O} 2 \text {, obs }}=\mathrm{K}_{\mathrm{O} 2 \text {, penta }} /\left(1+\mathrm{K}_{\mathrm{His}}\right)=\left(\mathrm{k}_{\mathrm{O} 2, \text { on }} / \mathrm{k}_{\mathrm{O} 2 \text {, off }}\right) /\left(1+\mathrm{k}_{\mathrm{His}, \text { on }}\right) / \mathrm{k}_{\mathrm{His}, \text { off }}\right)$

In order to attempt to measure the $\mathrm{O}_{2}$-dissociation rate of GLB-26, mixed atmosphere $\mathrm{O}_{2} / \mathrm{CO}$ experiments were performed. The oxy complex of GLB-26 is unstable (millisecond timescale). After $\mathrm{CO}$ dissociation, a first phase of rebinding was measured where three ligands are in competition $\left(\mathrm{O}_{2}, \mathrm{CO}\right.$ and His). A slow phase $\left(5 \mathrm{~s}^{-1}\right)$ was measured at equimolar ligand concentration $(\sim 500 \mu \mathrm{M}$ $\mathrm{O}_{2} / \mathrm{CO}$ ). This phase does not correspond to the $\mathrm{O}_{2}$ replacement by $\mathrm{CO}$, but rather to the $\mathrm{O}_{2}$-induced oxidation of the heme, because the initial CO-globin signal (before flash photolysis) decreases after each rebinding

cycle. Although a small fraction of transient $\mathrm{O}_{2}$-heme complex is replaced by $\mathrm{CO}$, the $\mathrm{k}_{\text {off }}\left(\mathrm{O}_{2}\right)$ is undistinguishable from that of the oxidation rate. $\mathrm{O}_{2}$ equilibrium measurements were tentatively run in the presence of the Hayashi reducing system. Even then, only ferric and deoxy globins were detected when changing $\mathrm{O}_{2}$ tensions, confirming that a stable oxy-derivative is not formed (Figure 6).

\section{In situ localisation}

Analysis of tissue-specific expression patterns revealed that $g l b-26$ is expressed exclusively in the head mesoder- 


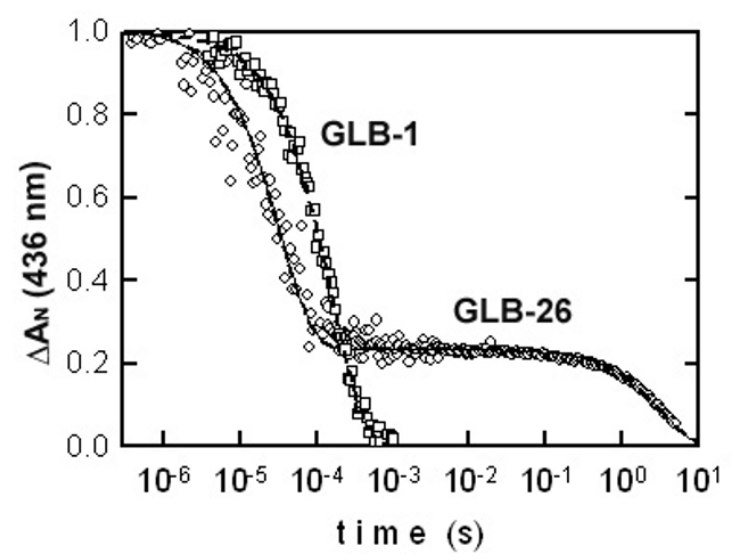

Figure $\mathbf{5}$ Ligand rebinding kinetics after flash photolysis. The kinetics of $C O$ rebinding is monophasic for the globin GLB-1 as expected for a pentacoordinate heme. The kinetics for GLB-26 is biphasic and follows a simple model of competition for heme rebinding between a distal residue and $\mathrm{CO}$.

mal cell (Figure 8A and $8 \mathrm{~B}$ ) and in the stomato-intestinal muscle (Figure $8 \mathrm{~A}$ and $8 \mathrm{C}$ ). The function of the head mesodermal cell is currently unknown. The stomatointestinal muscle connects the surfaces of the posterior intestinal cells to the ventral epidermis and is coupled to the anal sphincter and anal depressor muscles via gap junctions. Contraction of these muscles promotes defecation. $g l b-1$ is expressed mainly in a subset of neuronal cells and in head muscular tissue (Figure 8D, E and 8F). Both globin genes clearly display distinct expression patterns. Notably, the majority of C. elegans globins are expressed in the nervous system in highly cell-specific patterns [26].

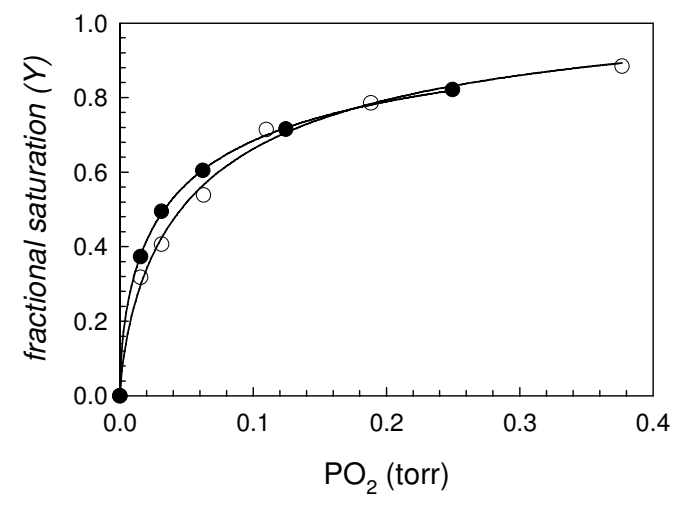

Figure $6 \mathrm{O}_{2}$ equilibrium curves of GLB-1 at pH 6.90 (open symbols) and pH 7.54 (closed symbols). Data fitting according to the Hill equation is shown. Solvent conditions: $100 \mathrm{mM}$ Hepes buffer, $0.5 \mathrm{mM}$ EDTA + Hayashi enzymatic reduction system [40].

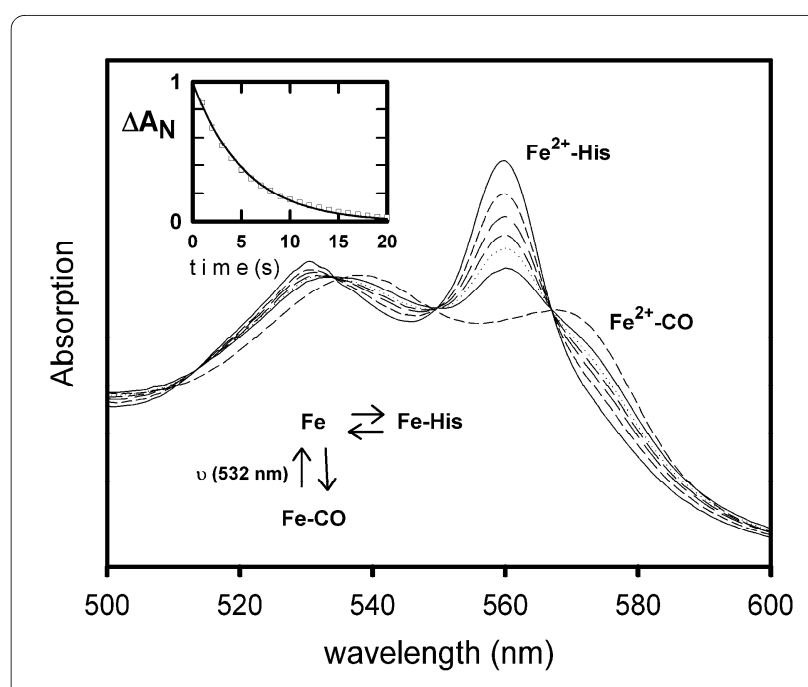

Figure $7 \mathrm{His}$ to CO replacement reaction of GLB-26. The variation of absorption that occurs on the timescale of seconds was recorded in the visible region with a diode-array spectrophotometer. For the series of spectra, a decrease in absorbance at $560 \mathrm{~nm}$ is observed for increasing times. The observed spectral change is the same as the difference between the static spectra for the His and $\mathrm{CO}$ bound forms; this unambiguously assigns the slow transition after $\mathrm{CO}$ photo-dissociation (Figure 6) to the replacement of the internal His residue by $\mathrm{CO}$. The insert shows the progression of the reaction, presented as the normalized fraction of the His bound form (the remainder in the CO bound form).

\section{Globin expression under hypoxic conditions}

To investigate hypoxic response, worms were subjected to hypoxia ( $0.1 \%$ oxygen) for $12 \mathrm{~h}$ in a hypoxic chamber, and globin gene expression levels were determined by quantitative real-time RT-PCR. Analysis of the expression profiles revealed significant upregulation for $g l b-1$ (1.72; P < 0.01) whereas expression levels of $g l b-26(0.93)$ remain unaffected by hypoxia (additional file 3 Figure S3).

\section{Discussion}

Gas exchange in C. elegans relies completely on diffusion from the surrounding environment into the tissues $[14,15]$. C. elegans has an extended network of 302 neurons. Neuronal signal transduction consumes high amounts of energy, which mainly originates from aerobic metabolism. Neurons have therefore developed various adaptation strategies against hypoxic stress, for example the expression of globin-like proteins. C. elegans globinlike proteins are mainly present in neurons. It is therefore possible that $C$. elegans globin-like proteins play a role in the defence against the toxic effects of hypoxia/anoxia by functioning in detoxification of ROS and RNS as well as in $\mathrm{O}_{2}$ sensing and/or that they may have a role in redox reactions, rather than functioning as $\mathrm{O}_{2}$ carriers, as proposed for Ngb $[27,28]$. 


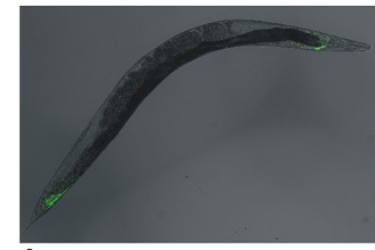

A
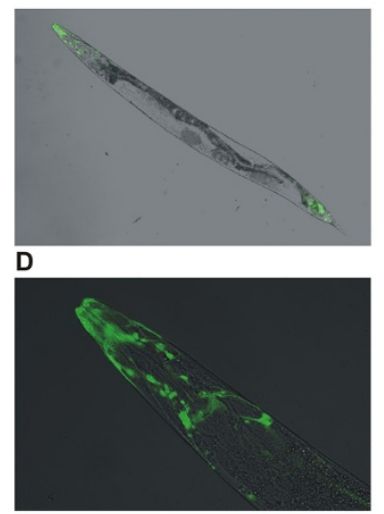

B

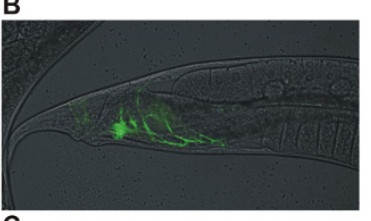

$\bar{E}$

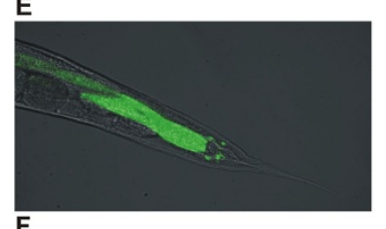

C

$\mathbf{F}$

Figure 8 Expression of globinpromotor::GFP fusions. (A) g/b26::GFP expression, (B) glb-26::GFP expression in head mesodermal cell, (C) glb-26::GFP expression in stomato-intestinal muscle, (D) glb-1::GFP expression, (E) g/b-1::GFP expression in the head, (F) g/b-1::GFP expression in the tail, background fluorescence is also visible in the posterior intestine.

Although the $C$. elegans genome codes for more than 30 globin-like proteins, which are all expressed as demonstrated by RT-PCR, no characteristic UV/VIS globin absorption spectrum can be detected in a crude C. elegans extract. This suggests that the overall in vivo protein concentrations are very low [11], which tallies with the possibility that some of the globin-like molecules (e.g. $g l b-1)$ are expressed only in a small subset of cells.

Expression of a selected set of $C$. elegans globins in an $E$. coli system in vitro, demonstrates that, under the conditions used, only GLB-1 and GLB-26 can be recovered as hemoproteins in the cytosolic fraction of the cell. Refolding of the others, starting from the apoprotein, purified from inclusion bodies, and adding hemin in vitro failed. When inspecting the sequences of the C. elegans globins, a correlation was found between the presence of long Nand/or C-terminal extensions and the expression in inclusion bodies as was also seen previously for Cygb [29]. The inability to refold several of the globin-like proteins may also suggest that some of these may not incorporate a heme group in vivo. Hence, they could support a function that does not require heme. Such consideration, however, does not exclude that these proteins may play a physiological role. Indeed, the $\mathrm{N}$-terminal domain of RsbR, a protein of the bacterial stressosomes (large signalling complexes that cope with environmental stress signalling) clearly displays the globin fold but is unable to bind heme [30]. Moreover, the N-terminal domain of
RsbR dimerizes in a fashion identical to that of the globin-coupled sensor, HemAT of Bacillus subtilis and Geobacter sulfurreducens [31]. It is hypothezised that in RsbR the globin-folded domain evolved from an ancestral sensor globin related to the globin-coupled sensors, but lost its ability to bind heme in later evolutionary stages $[3,30]$.

The UV/VIS and RR spectra of GLB-1 indicate that this globin is pentacoordinated in the deoxy form. The $v(\mathrm{Fe}-$ $\mathrm{CO}$ ) stretching mode, observed at $\sim 493 \mathrm{~cm}^{-1}$ has previously been observed in other globins, e.g. sperm whale $\mathrm{Mb}\left(491 \mathrm{~cm}^{-1}\right)$ [32]. In $\mathrm{Mb}$, this conformer becomes dominant at low $\mathrm{pH}$ values, when the distal HisE7 residue swings out of the heme pocket. In GLB-1 it is ascribed to an open conformation of the heme pocket, with a weak interaction between $\mathrm{CO}$ and the surrounding residues. No Fe-CO stretching modes at higher frequencies can be observed, in agreement with earlier observations on Paramecium caudatum $\mathrm{Hb}$ [33]. However, it should be noted that, since no isotopic labelling of the $\mathrm{CO}$ ligand was performed, weak Fe-CO stretching modes may escape attention. Unlike the $\mathrm{CO}$ form, the 3-D structure shows a stabilization of bound $\mathrm{O}_{2}$ through a hydrogen bond with TyrB10. Same is seen for $A$ suum $\mathrm{Hb}$ [34].

GLB-1 displays a quite high $\mathrm{O}_{2}$ affinity, mainly due to the slow $\mathrm{k}_{\text {off }}$ for $\mathrm{O}_{2}$. Because of the presence of the GlnE7/ TyrB10 heme distal pair, a high $\mathrm{O}_{2}$ affinity was expected. Nevertheless, the $\mathrm{O}_{2}$ affinity is almost 5 times lower than that of A. suum (46 $\mu \mathrm{M}^{-1}$ versus $\left.215 \mu \mathrm{M}^{-1}\right)$. This difference is mainly due to a slower $\mathrm{O}_{2}$ dissociation process in A. suum $\mathrm{Hb}\left(0.013 \mathrm{~s}^{-1}\right)$ than in GLB-1 $\left(0.05 \mathrm{~s}^{-1}\right)$, related to strong stabilization of the bound $\mathrm{O}_{2}$ by two hydrogen bonds, a short one with TyrB10 (2.73 $\AA$ ) and a weaker one with GlnE7 (3.30 $)$ [6]. In GLB-1 TyrB10 also stabilizes the bound oxygen $(3.01 \AA)$, but the Fe---O1 coordination bond is longer than that in A. suum $\mathrm{Hb}$. Therefore it is easier to break, resulting in a lower $\mathrm{O}_{2}$ affinity compared with $A$. suum $\mathrm{Hb}$. The nemertean C. lacteus mini-Hb also displays a TyrB10/GlnE7 pair, but displays high rates of $\mathrm{O}_{2}$ dissociation $\left(k_{\text {off }}\left(\mathrm{O}_{2}\right) \sim 200-600 \mathrm{~s}^{-1}\right)$ and hence a moderate $\mathrm{O}_{2}$ affinity $\left(K_{\mathrm{O} 2} \sim 1 \mu \mathrm{M}^{-1}\right)$ as a result of a third polar residue, ThrE11, in its distal site. In fact, the presence of Thr at position E11 modulates the formation of a hydrogen bond between TyrB10 and the heme-bound $\mathrm{O}_{2}$ [35].

UV/VIS spectra similar to those of ferrous GLB-26 were observed for the ferrous forms of Ngb [36], and Cygb [37]. The spectra are typical of ferrous globins exhibiting bis-histidine heme coordination. The $v(\mathrm{Fe}-$ $\mathrm{CO})$ stretching mode of CO-ligated ferrous GLB-26 is situated at $\sim 493 \mathrm{~cm}^{-1}$, again typical of an open conformation of the heme pocket. No clear $v(\mathrm{Fe}-\mathrm{CO})$ modes were observed at higher frequencies, in contrast to other heme 
proteins exhibiting bis-histidine coordination, such as $\mathrm{Ngb}$, which exhibits three intense $\mathrm{Fe}-\mathrm{CO}$ stretching modes (one open and two closed conformations) [37].

The biphasic plot observed for the GLB-26 CO-rebinding kinetics results from the competition between $\mathrm{CO}$ and the distal HisE7 ligand. The slow phase of replacement indicates that the dissociation of the distal E7 residue is slow. For most hexacoordinated globin samples equilibrated under $1 \mathrm{~atm} \mathrm{CO}$, this phase is only a few percent. The calculated $\mathrm{k}_{\text {on }}$ value for the distal ligand His $\left(20000 \mathrm{~s}^{-1}\right)$ is the highest ever measured for a hexacoordinated globin (one order of magnitude larger than for $\mathrm{Ngb}$ ) $[36,38]$. Also note that the $\mathrm{K}_{\mathrm{CO}}$ of GLB-26 is about one order of magnitude lower than that of Ngb (Table 1). This is in agreement with the RR results indicating an open conformation of the GLB-26 CO-ligated form. In Ngb, closed conformations have been identified [37].

Concerning the rates of $\mathrm{O}_{2}$-binding, both equilibrium and flash photolysis data confirm that GLB-26 is not capable of reversible $\mathrm{O}_{2}$ binding, and hence cannot act as an $\mathrm{O}_{2}$ store. Other globins, like Ngb, Cygb, 2-on-2 (truncated) hemoglobins and globin-coupled sensors, clearly illustrate different possible functions for members of the globin superfamily $[3,39,40]$. The tissue distribution of $\mathrm{Ngb}$, Cygb and the hypoxia-inducible myoglobin expression in non-muscle tissues in fish supports the hypothesis that globins may occur in every cell [41].

Additional in vivo analysis underscores the different behaviour of GLB-1 and GLB-26. GFP reporter assays revealed a clearly distinct expression pattern of $g l b-1$ and $g l b-26$. In addition both globins behave differently under hypoxic conditions $\left(0.1 \% \mathrm{O}_{2}\right)$; glb- 1 is significantly upregulated under hypoxia, whereas expression of $g l b-26$ remains unchanged. Strikingly, the opposite was observed under conditions of total anoxia; whereas the expression level of $g l b-1$ is unaffected, expression of $g l b$ 26 is induced.

\section{Conclusion}

GLB-1 and GLB-26 are fundamentally different relative to their tissue localisation, expression pattern under hypoxia and anoxia, ligand-binding mechanism and affinities. Ferrous GLB- 1 binds $\mathrm{O}_{2}$ with a high affinity and is pentacoordinated in the absence of exogenous heme ligands. Taken together, the observed functional data suggest for GLB-1 a putative role in vivo related to $\mathrm{O}_{2}$ binding, $\mathrm{NO}$ scavenging or $\mathrm{O}_{2}$ storage. This globin could serve to maintain the $\mathrm{O}_{2}$ concentration at a constant level provided that its cellular concentration is high enough. The induced GLB-1 expression under hypoxia conditions is consistent with a possible role in oxygen-dependent metabolism. Similar hypoxia-dependent inductions have been reported for globins putatively involved in oxygen transport or storage [42,43]. Interestingly, several hypoxia-tolerant organisms including Daphnia, Danio rerio and Carassius auratus display upregulation of pentacoordinated globins upon hypoxic exposure [44-47]. Furthermore, the oxygenated globin could play a role in regulating NO-homeostasis.

Ferrous GLB-26 globin cannot serve such functions due to its inability to form a stable oxygenated species. It can be speculated that at high $\mathrm{O}_{2}$ levels GLB-26 will readily reduce $\mathrm{O}_{2}$; the reduced species may then participate in redox reactions or simply dismutate into $\mathrm{O}_{2}$ and $\mathrm{H}_{2} \mathrm{O}_{2}$. GLB-26 may thus resemble oxidases. Under anaerobic conditions, this globin might participate in other redox reactions. Indeed, the very high GLB-26 heme affinity for the distal HisE7 residue points to roles other than binding gaseous ligands. Interestingly, an $\mathrm{N}$-terminal myristoylation site is predicted http://expasy.org/ with very high confidence (98.2\%) for GLB-26, which may indicate membrane anchoring, an unprecedented globin function [48].

\section{Methods}

\section{Recombinant expression of $C$. elegans globins}

C. elegans worms were grown as described previously [10]. Young adult worms were collected and total RNA was prepared using the TriZol method (Invitrogen) followed by $\mathrm{LiCl}$ precipitation (Ambion). The cDNA of the C. elegans globins was prepared using the OneStep RTPCR kit (Qiagen) and gene-specific primers (Eurogentec). Cycling conditions were as followed: $30 \mathrm{~min}$ at $50^{\circ} \mathrm{C}$ for the $\mathrm{RT}$ reaction, followed by $15 \mathrm{~min}$ at $95^{\circ} \mathrm{C}$ for the activation of the HotStar Taq DNA polymerase, followed by 35 cycles of $60 \mathrm{sec}$ at $94^{\circ} \mathrm{C}, 60 \mathrm{~s}$ at $54^{\circ} \mathrm{C}$ and $90 \mathrm{~s}$ at $72^{\circ} \mathrm{C}$. The cDNA was cloned into the pET3a vector (Stratagene) using NdeI and BamHI restriction enzymes (Biolabs, Westburg) and T4 Ligase (Novagen).

Mutations (Cys T Ser) were introduced in GLB-1 using the QuickChange ${ }^{\mathrm{Tm}}$ site-directed mutagenesis method (Stratagene) as described previously [36]. The mutant bearing the CysGH2 T Ser substitution is annotated as GLB-1*.

Cloning and expression of C. elegans globins were performed as described previously [36]. Briefly, the expression plasmids were transformed into Escherichia coli strain BL21(DE3)pLysS (Invitrogen). Cells were grown at $25^{\circ} \mathrm{C}$ in $\mathrm{TB}$ medium containing $200 \mu \mathrm{g} / \mathrm{ml}$ ampicillin, 30 $\mu \mathrm{g} / \mathrm{ml}$ chloramphenicol and $1 \mathrm{mM} \delta$-amino-levulinic acid. The culture was induced at $\mathrm{A}_{550}=0.8 \mathrm{OD}$ with IPTG (final concentration $0.04 \mathrm{mM}$ ).

\section{Purification of recombinant $C$. elegans globins}

After overnight growth, E. coli cells were collected. Recombinant GLB-1 and GLB-26 were spectroscopically localised in the cytosolic fraction. GLB-1 was purified to 
homogeneity using (i) ammonium sulphate precipitation (40\%-90\% saturation) after which the $90 \%$ pellet was dis-

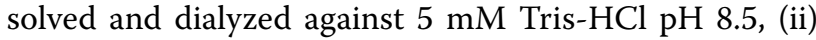
DEAE-Sepharose fast flow chromatography (step elution in $5 \mathrm{mM}$ Tris- $\mathrm{HCl} \mathrm{pH} \mathrm{8.5,} 200 \mathrm{mM} \mathrm{NaCl}$ ) and (iii) Sephacryl S200 gel filtration in $50 \mathrm{mM}$ Tris- $\mathrm{HCl} \mathrm{pH}$ 8.5, 150 $\mathrm{mM} \mathrm{NaCl}, 0.5 \mathrm{mM}$ EDTA. The globin fractions were pooled and concentrated.

GLB-26 was purified using (i) ammonium sulphate precipitation (60\% saturation), (ii) CM-sepharose fast-flow chromatography $(50 \mathrm{mM}$ sodium phosphate buffer $\mathrm{pH} 7$, step elution in $50 \mathrm{mM}$ sodium phosphate buffer $\mathrm{pH} 7,0$ $300 \mathrm{mM} \mathrm{NaCl}$ ) and (iii) S-Sepharose column $(50 \mathrm{mM}$ sodium phosphate buffer, step elution in $50 \mathrm{mM}$ sodium phosphate buffer $\mathrm{pH} 7,0-500 \mathrm{mM} \mathrm{NaCl}$ ).

After expression, C. elegans globins, GLB-7, GLB-13, GLB-14, GLB-18, GLB-23 and GLB-29 were localised as apo-protein in inclusion bodies. The standard purification procedure was as follows: cells were suspended in 50 $\mathrm{mM}$ Tris- $\mathrm{HCl} \mathrm{pH}$ 7.5, $0.5 \mathrm{M} \mathrm{NaCl}, 1 \mathrm{mM}$ EDTA, $1 \mathrm{mM}$ phenylmethylsulfonylfluorid and $5 \mathrm{mM}$ dithiotreitol. After suspension, $1 / 10$ volume of $10 \%$ triton X-100, 10\% deoxycholic acid, $500 \mathrm{mM}$ Tris- $\mathrm{HCl} \mathrm{pH}$ 7.5, $20 \mathrm{mM}$ EDTA was added and the cells were exposed to three freeze-thaw cycles and sonication until complete lysis. Inclusion bodies were isolated by centrifugation at 3,300 $\mathrm{g}$ for $10 \mathrm{~min}$ and the pellet was suspended in and washed three times with $1 \%$ triton X-100, 1 mM EDTA and 50 $\mathrm{mM}$ Tris- $\mathrm{HCl} \mathrm{pH}$ 7.5. Inclusion bodies were solubilized in $6 \mathrm{M}$ guanidinium hydrochloride, $50 \mathrm{mM}$ Tris- $\mathrm{HCl} \mathrm{pH}$ 7.5 and $1 \% 2$-mercaptoethanol for $1 \mathrm{hr}$ at $0^{\circ} \mathrm{C}$. After elimination of the insoluble material by centrifugation $(10$ $\min 10,000 \mathrm{~g}$ ), the C. elegans globins were refolded by adding a $1.4 \mathrm{M}$ excess of hemin and dialysis against $5 \mathrm{mM}$ Tris- $\mathrm{HCl} \mathrm{pH} 8.5$ at $4^{\circ} \mathrm{C}$. The refolded C. elegans globins were further purified using Sephacryl S200 gelfiltration in $50 \mathrm{mM}$ Tris- $\mathrm{HCl}, \mathrm{pH} 8.5,150 \mathrm{mM} \mathrm{NaCl}, 0.5 \mathrm{mM}$ EDTA.

When no heme was incorporated into the C. elegans globins by this approach, other methods were tried. For details see additional file 4 .

\section{Optical and Resonance Raman spectroscopy}

UV/VIS spectroscopy was performed on a Cary-5 UV/ VIS-NIR spectrophotometer. All optical spectra were measured in a 200-800 $\mathrm{nm}$ range. Resonance Raman (RR) measurements were carried out on an $80-\mathrm{cm}$ Dilor XY800 Raman scattering spectrometer consisting of a triple spectrograph operating in normal mode and a liquid nitrogen-cooled CCD detector. The excitation source was a Kr-ion laser (Spectra Physics 2020) at $413.1 \mathrm{~nm}$. The protein solution was stirred at 6,000 rpm to avoid local heating. Five spectra (120-s recording time) were acquired and averaged after the removal of cosmic ray spikes by a program developed in-house. Laser powers of
1 and 50 milliWatt were used. For UV/VIS RR spectroscopy, the CO-ligated ferrous forms of the C. elegans globins were prepared by adding an excess of sodium dithionite and subsequently passing the sample through a PD10 column (Amersham Biosciences) equilibrated with CO-flushed Tris- $\mathrm{HCl}$ buffer (5 mM, pH 8.5). The deoxy ferrous form was obtained by equilibration under nitrogen and by addition of an excess of sodium dithionite. The concentration of the protein samples used for optical and RR measurements was typically $\sim 60 \mu \mathrm{M}$ in Tris- $\mathrm{HCl}$ buffer (5 mM, pH 8.5).

\section{Crystallization and X-ray Data Collection}

Crystallization of GLB-1* was achieved using the hanging dropvapour diffusion setup. In the material used for crystallization the $\mathrm{Fe}^{2+}-\mathrm{O}_{2}$ form is the predominant form. Using the fully oxygenated and oxidized spectra of $\mathrm{Mb}$ as reference, a deconvolution of the UV/Vis spectra resulted in $30 \%( \pm 5 \%)$ ferric form and $70 \%( \pm 5 \%) \mathrm{Fe}^{2+}-\mathrm{O}_{2}$ form. The GLB-1* solution, at $35 \mathrm{mg} / \mathrm{ml}$, was equilibrated against a precipitant solution containing $3.0 \mathrm{M}$ ammonium sulphate and $10 \%$ glycerol (v/v), at $277 \mathrm{~K}$. Rod-like crystals grew in about 2-3 weeks. The crystals were transferred in a solution containing $3.3 \mathrm{M}$ ammonium sulphate and $20 \%$ glycerol $(\mathrm{v} / \mathrm{v})$ immediately prior to data collection (at $100 \mathrm{~K}$ ). These crystals diffracted up to $2.8 \AA$ resolution using synchrotron radiation (beamline ID14-3, ESRF, Grenoble, France; trigonal space group $P 3_{1} 21$ (or enantiomorph), with unit cell parameters: $a=b=77.7 \AA$, $c=145.6 \AA$, two GLB-1* molecules per asymmetric unit).

In order to obtain better quality crystals, a wider screen (566 in-house-designed conditions) was set up, using the sitting dropvapour diffusion method and a robotic apparatus (Genesis RSP100 - Tecan). Large single crystals grew within 2-3 weeks using PEG $4 \mathrm{k} 10 \%$, $0.1 \mathrm{M}$ sodium acetate ( $\mathrm{pH} 5.5)$ at $277 \mathrm{~K}$. They were transferred in a solution containing 30\% PEG $4 \mathrm{k}, 0.1 \mathrm{M}$ sodium acetate $(\mathrm{pH}$ $5.5)$, and $15 \%(\mathrm{v} / \mathrm{v})$ glycerol, immediately prior to cryocooling and data collection. A three-wavelength multiwavelength anomalous dispersion (MAD) data set was collected at ESRF synchrotron (beamline ID29, Grenoble, France) at $100 \mathrm{~K}$. The peak and inflection point wavelengths were determined by collecting an X-ray absorption spectrum near the heme iron atom $\mathrm{K}$ absorption edge. The crystals diffracted up to $1.5 \AA$ resolution (remote wavelength data set) and belong to the tetragonal $\mathrm{P}_{3} 2_{1} 2$ space group (or enantiomorph), with unit cell parameters: $a=b=81.9 \AA$ А $c=47.0 \AA$ (one GLB-1* molecule per asymmetric unit). All collected data were reduced and scaled using MOSFLM and SCALA, respectively $[49,50]$. Data collection and processing statistics are reported in additional file 2 . 


\section{Structure Determination and Refinement}

MAD phases, based on the heme-Fe atom anomalous signal, were determined on the tetragonal crystal form (space group $P 4_{3} 2_{1} 2$ ) at $1.9 \AA$ resolution with SOLVE [51] with a figure of merit of 0.37 . The electron density map was improved by solvent flattening with DM [52] yielding a figure of merit of 0.86. ARP/wARP [53] was used to extend and refine phases to $1.5 \AA$ resolution, and for automated model building of all the main and side chain atoms. The molecular model was subsequently checked manually with COOT $[53,54]$ and refined to the maximum resolution (1.5 $⿱$ ) using REFMAC [55]. At the end of the refinement stages (including anisotropic B-factor refinement), a heme-bound dioxygen and 202 solvent molecules were located through inspection of difference Fourier maps.

The refined structure of the GLB-1* monomer was then used as a starting model to solve the structure of the trigonal crystal form using the program MOLREP [56]. The rotational and translational searches yielded two prominent solutions in the 34.3-2.8 A resolution range for space group $P 3_{1} 21$. Initially the two GLB-1* molecules were rigid-body refined using the program REFMAC [55]. At the end of the restrained refinement cycles 46 water molecules were located through the inspection of difference Fourier maps, using the program COOT [54].

The programs Procheck and Surfnet $[19,57]$ were used to assess stereochemical quality and to explore protein matrix cavities. The program PISA [23] was used to analyse quaternary assemblies within the crystal unit cell. Atomic coordinates and structure factors have been deposited with the Protein Data Bank [58] with entry codes $2 \mathrm{wtg}$ and $\mathrm{r} 2 \mathrm{wtgsf}(1.5 \AA$ resolution) and $2 \mathrm{wth}$ and r2wthsf (2.8 Å resolution), respectively.

\section{Ligand binding}

\section{Kinetic measurements}

Ligand-binding kinetic measurements were performed by laser photodissociation as described elsewhere [59]. Samples were equilibrated under air or $0.1 \mathrm{~atm}$ or $1 \mathrm{~atm}$ $\mathrm{CO}$. For oxygen dissociation rates $\left(\mathrm{k}_{\mathrm{off}}\right)$, the ligand replacement reaction was use: a mixed $\mathrm{CO} / \mathrm{O}_{2}$ atmosphere was used; photodissociation of $\mathrm{CO}$ allows association of oxygen followed by a return to the $\mathrm{CO}$ form. Kinetics were measured and recorded at various wavelengths alternatively on a LeCroy oscilloscope for microsecond to second timescales and a diode-array HP8453 spectrophotometer for longer times. The experiments were performed in a $50 \mathrm{mM}$ potassium phosphate, 0.1 mM EDTA buffer at $\mathrm{pH} 7.0$ and $25^{\circ} \mathrm{C}$.

\section{Equilibrium experiments}

Ferric C. elegans globin samples were reduced anaerobically by dialysis against $\mathrm{CO}$-equilibrated $50 \mathrm{mM}$ Hepes buffer, $0.5 \mathrm{mM}$ EDTA, pH 7.6, containing $2 \mathrm{mg} / \mathrm{ml}$ sodium dithionite and DTT as described [40] and stored in aliquots at $-80^{\circ} \mathrm{C}$ as $\mathrm{CO}$-derivative. Samples were thawed shortly before measurements and kept on ice until analysed.

$\mathrm{O}_{2}$ equilibrium curves of 3- $\mu \mathrm{l}$ samples of GLB-1 were recorded at $20^{\circ} \mathrm{C}$ by monitoring absorbance at $436 \mathrm{~nm}$ using a thin-layer equilibration chamber fed by cascaded Wösthoff gas mixing pumps that deliver a constant flow of precise mixtures of air or $\mathrm{O}_{2}$ and ultrapure ( $\left.>99.998 \%\right)$ $\mathrm{N}_{2}$ [60]. Samples were dissolved in $0.1 \mathrm{M}$ Hepes buffer, 0.5 $\mathrm{mM}$ EDTA at a protein concentration of $0.3 \mathrm{mM}$ heme, and contained the enzymatic met- $\mathrm{Hb}$ reducing system as previously detailed [40,61]. Before determination of $\mathrm{O}_{2}$ equilibria, $\mathrm{CO}$ was removed from the heme by repeated cycles of $\mathrm{N}_{2} / \mathrm{O}_{2}$ equilibration within the chamber until the absorbance difference between $\mathrm{N}_{2}$ and $\mathrm{O}_{2}$ equilibrated samples remained constant.

\section{Expression analysis under hypoxia}

For hypoxia treatments, plates containing synchronized young adult worms were placed either in room air (normoxia control) or in a hypoxic chamber (MIC-101, Billups-Rothenberg Inc.) with constant gas flow. Worms were incubated for $12 \mathrm{~h}$ in $21 \%$ oxygen or $0.1 \%$ oxygen at $20^{\circ} \mathrm{C}$. Animals were quickly harvested in S-buffer $(43.55$ $\mathrm{mM} \mathrm{KH2PO4,} 6.45 \mathrm{mM}$ K2HPO4 and $100 \mathrm{mM} \mathrm{NaCl}$ in distilled water, $\mathrm{pH}$ 6), RNA was extracted using the RNeasy Midi kit (Qiagen) according to the manufacturer's instructions. All samples were treated with DNase (Zymo Research). A NanoDrop ND 1000 spectrophotometer (Isogen) was used to analyze RNA concentration and purity. First strand cDNA was synthesized from $2 \mu \mathrm{g}$ RNA using an oligo(dT) primer and Moloney murine leukemia virus reverse transcriptase (Fermentas) at $42^{\circ} \mathrm{C}$ for $1 \mathrm{hr}$. Quantitative RT-PCR was carried out using a RotorGene 2000 centrifugal real-time cycler (Corbett Research) using the Platinum SYBR Green qPCR SuperMix-UDG (Invitrogen) as described previously [62]. A single melt peak for each reaction confirmed the identity of each PCR product. The threshold cycle $(\mathrm{Ct})$ values of the Rotor-Gene software version 6.0 (Corbett Research) were exported to qBase version 1.3.5 [63] for further analysis. All measurements were produced in duplicate, and for each primer set, reaction efficiency estimates were derived from standard curves that were generated using serial dilutions of a cDNA pool of normoxic and hypoxic nematode samples. These were then used by qBase to transform the $\mathrm{Ct}$ values to relative quantities that were normalized using the geometric mean of three reference genes (tba-1, $c s q-1$ and $c d c-2)$ identified by the geNorm 3.4 software from a set of 8 candidate control genes [64]. The significance of data was evaluated by Student's t-test.

\section{Expression patterns}

5 ' upstream sequences from $g l b-26$ and $g l b-1$ were extracted from the UCSC Genome Browser database 
using a repeat masker function http://genome.ucsc.edu. Putative promoters were derived from wild-type N2 genomic DNA by PCR. Promoter::green fluorescent protein (GFP) fusion constructs were made as described by Hobert [65]. In this procedure two primary PCR products, the globin promoter (1108 bp for glb-26, 2294 bp for $g l b-1)$ and the GFP encoding sequence plus the 3'UTR from unc-54 amplified from a fire's vector pPD95.75, are fused in frame in a subsequent fusion PCR employing nested primers.

Microinjection was carried out by injecting DNA into the gonads of young adult hermaphrodites using an AxioVert 135 (Zeiss) microscope and FemtoJet microinjection system (Eppendorf). For each promoter-GFP fusion construct 20 to 30 wild-type N2 worms were injected. The pRF4 plasmid was co-injected with the promoterreporter fusion construct at concentrations of $100 \mathrm{ng} / \mu \mathrm{l}$ and $50 \mathrm{ng} / \mu \mathrm{l}$, respectively. pRF4 contains the dominant marker rol-6(su1006) which confers a rolling phenotype allowing easy identification of transformed worms. Rolling first generation (F1) progeny were picked after four days of incubation at $20^{\circ} \mathrm{C}$ and checked for rolling F2 progeny after a further three- to four-day incubation period. At least 3 independent transgenic lines were examined for both globin genes. For imaging, worms were mounted on agarose pads and immobilized with 10 $\mathrm{mM}$ sodium azide. Images were taken using a D-Eclipse C1 Confocal Microscope (Nikon).

\section{Accession numbers}

Atomic coordinates and structure factors have been deposited with the Protein Data Bank [58] with entry codes $2 \mathrm{wtg}$, and $\mathrm{r} 2 \mathrm{wtgsf}(1.5 \AA$ resolution), and $2 \mathrm{wth}$, and $\mathrm{r} 2 \mathrm{wthsf}(2.8 \AA$ resolution), respectively.

\section{Additional material}

\section{Additional file 1 Characteristics of the C. elegans globins studied. A}

table with all characteristics of the globins studied and an allignement of all globin sequences of C.elegans.

Additional file 2 Data collection and refinement statistics for GLB-1*

Contains the data collection and refinement statistics and the stereochemical analysis of GLB- $1 *$ crystal structure.

Additional file 3 Globin expression levels under hypoxic conditions. Graph of globin expression levels under hypoxic conditions.

Additional file 4 Purification of Recombinant C. elegans globins.

detailed protocol for the purification of all studied globins.

\section{Abbreviations}

Hb: hemoglobin; Mb: myoglobin; Ngb: neuroglobin; Cygb: cytoglobin; RR: Resonance Raman; MAD: Multi-wavelength anomalous dispersion; rmsd: root mean square deviations; GFP: green fluorescent protein; HS: High spin; LS: Low spin; CM-sepharose: Carboxy methyl sepharose; S-sepharose: sulphopropyl sepharose; NIR: near infra red; 'as purified': refers to globin samples obtained after purification without additional modification in ligand binding.

\section{Authors' contributions}

EG carried out the expression cloning with help of LT, purified the globins and drafted the manuscript; DH and SDH generated fusion constructs, performed microinjection experiments and analyzed globin expression levels under hypoxic conditions. MN, AP and MB carried out the 3D-structural determination of GLB-1*. EV and SVD carried out the UV-VIS spectroscopy and Resonance Raman measurements. AF and RW carried out the equilibrium measurements, $M M$ and $L K$ the kinetic measurements. LM, JV and SD were responsible for the study design and coordination of it. All authors read and approved the final document.

\section{Acknowledgements}

$\mathrm{DH}$ is a postdoctoral fellow and EV a research assistant of the Fund for Scientific Research (FWO). SVD thanks the FWO for financial support (G.0468.03N). Financial support to SD, LM, and EG was provided by BOF UA TOP 2006 and to SD, LM, JV, SVD by FWO project G.0247.09. AF and REW were supported by the Danish Natural Science Research Council and the Novo Nordisk, Lunbeck and Carlsberg Foundations. MB acknowledges grants from the Italian Ministry of University and Scientific Research (FIRB project "Biologia Strutturale" RBLA03B3KC_005) and from the University of Milano (Italy). MCM and LK are supported by Inserm and the Univ. Paris 11.

\section{Author Details}

'Department of Biomedical Sciences, University of Antwerp, Universiteitsplein 1, B-2610 Antwerp, Belgium, 2Institute of Physiology and Zürich Center for Integrative Human Physiology (ZIHP), University of Zürich, Winterthurerstrasse 190, CH-8057, Zürich, Switzerland, ${ }^{3}$ Department of Biomolecular Sciences and Biotechnology, University of Milano, Via Celoria 26, I-20133 Milano, Italy, ${ }^{4}$ Department of Physics, University of Antwerp, Universiteitsplein 1, B-2610 Antwerp, Belgium, ${ }^{5}$ Department of Physics, University of Genova, Via Dodecaneso 33 I-16146 Genova, Italy, 6INSERM U779, University of Paris 11, Hopital de Bicetre, Le Kremlin Bicêtre, 94275, France, 'Zoophysiology, Department of Biological Sciences, Aarhus University, C F Møllers Allé, Bygning 1131, DK-8000 Aarhus C, Denmark and ${ }^{8}$ Department of Biology, Ghent University, K L Ledeganckstraat 35, B-9000 Ghent, Belgium

Received: 13 November 2009 Accepted: 2 April 2010 Published: 2 April 2010

\section{References}

1. Vinogradov SN, Hoogewijs D, Bailly X, Arredondo-Peter R, Guertin M, Gough J, et al:: Three globin lineages belonging to two structural classes in genomes from the three kingdoms of life. Proc Natl Acad SCl USA 2005, 102:11385-11389

2. Weber RE, Vinogradov SN: Nonvertebrate hemoglobins: functions and molecular adaptations. Physiol Rev 2001, 81:569-628.

3. Freitas TA, Saito JA, Hou S, Alam M: Globin-coupled sensors, protoglobins, and the last universal common ancestor. J/norg Biochem 2005, 99:23-33.

4. Vinogradov SN, Moens L: Diversity of globin function: enzymatic, transport, storage, and sensing. J Biol Chem 2008, 283:8773-8777.

5. Blaxter M: Nemoglobins: Divergent nematode globins. Parasitology Today 1993, 9:353-360.

6. Goldberg DE: The enigmatic oxygen-avid hemoglobin of Ascaris. Bioessays 1995, 17:177-182.

7. Yang J, Kloek AP, Goldberg DE, Mathews FS: The structure of Ascaris hemoglobin domain I at 2.2 A resolution: molecular features of oxygen avidity. Proc Nat/ Acad Sci USA 1995, 92:4224-4228.

8. Xia Z, Zhang W, Nguyen BD, Mar GN, Kloek AP, Goldberg DE: 1H NMR investigation of the distal hydrogen bonding network and ligand tilt in the cyanomet complex of oxygen-avid Ascaris suum hemoglobin. J Biol Chem 1999, 274:31819-31826.

9. Minning DM, Gow AJ, Bonaventura J, Braun R, Dewhirst M, Goldberg DE, et al:: Ascaris haemoglobin is a nitric oxide-activated 'deoxygenase'. Nature 1999, 401:497-502.

10. Hoogewijs D, Geuens E, Dewilde S, Moens L, Vierstraete A, Vinogradov S et al:: Genome-wide analysis of the globin gene family of $C$. elegans. IUBMB Life 2004, 56:697-702.

11. Hoogewijs D, Geuens E, Dewilde S, Vierstraete A, Moens L, Vinogradov S, et al:: Wide diversity in structure and expression profiles among members of the Caenorhabditis elegans globin protein family. BMC Genomics 2007, 8:356. 
12. Hankeln T, Friedl H, Ebersberger I, Martin J, Schmidt ER: A variable intron distribution in globin genes of Chironomus: evidence for recent intron gain. Gene 1997, 205:151-160.

13. Baumgarthl $\mathrm{H}$, Kritzler $\mathrm{K}$, Zimelka W, Zinkler D: Local $\mathrm{PO}_{2}$ measurements in the environment of submerged soil microarthroods. Acta Oecologica 1994, 15:781-789.

14. Paget TA, Fry M, Lloyd D: Effects of inhibitors on the oxygen kinetics of Nippostrongylus brasiliensis. Mol Biochem Parasitol 1987, 22:125-134.

15. Atkinson HJ: Respiration in nematodes. Nematodes as biological models 1980:101-142.

16. Gray JM, Karow DS, Lu H, Chang AJ, Chang JS, Ellis RE, et al:: Oxygen sensation and social feeding mediated by a C. elegans guanylate cyclase homologue. Nature 2004, 430:317-322.

17. Van Voorhies WA, Ward S: Broad oxygen tolerance in the nematode Caenorhabditis elegans. J Exp Biol 2000, 203:2467-2478.

18. Engh RA, Huber R: Accurate bond and angle parameters for X-ray protein structure refinement. Acta Crystallogr A 1991, 47:392-400.

19. Laskowski RA, MacArthur MW, Moss DS, Thornton JM: PROCHECK, a program to check the stereochemical quality of protein structures. $J$ App/ Crystallogr 1993, 26:283-291.

20. Holm L, Sander C: Structural alignment of globins, phycocyanins and colicin A. FEBS Lett 1993, 315:301-306.

21. Bolognesi M, Bordo D, Rizzi M, Tarricone C, Ascenzi P: Nonvertebrate hemoglobins: structural bases for reactivity. Prog Biophys Mol Biol 1997, 68:29-68.

22. Perutz MF: Regulation of oxygen affinity of hemoglobin: influence of structure of the globin on the heme iron. Annu Rev Biochem 1979, 48:327-386

23. Krissinel E, Henrick K: Detection of protein assemblies in Crystals. In Complife 2005, LNBI 3695 Edited by: Berthold. Berlin Heidelberg: SringerVerlag; 2005:163-174.

24. Royer WE Jr, Hendrickson WA, Chiancone E: The 2.4-Â crystal structure of Scapharca dimeric hemoglobin. Cooperativity based on directly communicating hemes at a novel subunit interface. J Biol Chem 1989, 264:21052-21061

25. Mitchell DT, Kitto GB, Hackert ML: Structural analysis of monomeric hemichrome and dimeric cyanomet hemoglobins from Caudina arenicola. J Mol Biol 1995, 251:421-431.

26. Hoogewijs D, De Henau S, Dewilde S, Moens L, Couvreur M, Borgonie G, et al: The Caenorhabditis globin gene family reveals extensive nematodespecific radiation and diversification. BMC Evol Biol 2008, 8:279.

27. Brunori M, Giuffre A, Nienhaus K, Nienhaus GU, Scandurra FM, Vallone B: Neuroglobin, nitric oxide, and oxygen: functional pathways and conformational changes. Proc Natl Acad Sci USA 2005, 102:8483-8488.

28. Fago A, Hundahl C, Malte H, Weber RE: Functional properties of neuroglobin and cytoglobin. Insights into the ancestral physiological roles of globins. IUBMB Life 2004, 56:689-696.

29. Geuens E, Brouns I, Flamez D, Dewilde S, Timmermans JP, Moens L: A globin in the nucleus! J Biol Chem 2003, 278:30417-30420.

30. Murray JW, Delumeau O, Lewis RJ: Structure of a nonheme globin in environmental stress signaling. Proc Natl Acad Sci USA 2005, 102:17320-17325

31. Zhang W, Phillips GN Jr: Structure of the oxygen sensor in Bacillus subtilis: signal transduction of chemotaxis by control of symmetry. Structure 2003, 11:1097-1110.

32. Sage JT, Morikis D, Champion PM: Spectroscopic studies of myoglobin at low pH: heme structure and ligation. Biochemistry 1991, 30:1227-1237.

33. Das TK, Weber RE, Dewilde S, Wittenberg JB, Wittenberg BA, Yamauchi K, et al: Ligand binding in the ferric and ferrous states of Paramecium hemoglobin. Biochemistry 2000, 39:14330-14340.

34. Huang S, Huang J, Kloek AP, Goldberg DE, Friedman JM: Hydrogen bonding of tyrosine B10 to heme-bound oxygen in Ascaris hemoglobin. Direct evidence from UV resonance Raman spectroscopy. J Biol Chem 1996, 271:958-962.

35. Pesce A, Nardini M, Ascenzi P, Geuens E, Dewilde S, Moens L, et al:: Thr-E11 regulates $\mathrm{O} 2$ affinity in Cerebratulus lacteus mini-hemoglobin. $J$ Biol Chem 2004, 279:33662-33672.

36. Dewilde S, Kiger L, Burmester T, Hankeln T, Baudin-Creuza V, Aerts T, et al:: Biochemical characterization and ligand binding properties of neuroglobin, a novel member of the globin family. J Biol Chem 2001, 276:38949-38955.
37. Sawai H, Makino M, Mizutani Y, Ohta T, Sugimoto H, Uno T, et al:: Structural characterization of the proximal and distal histidine environment of cytoglobin and neuroglobin. Biochemistry 2005 44:13257-13265

38. Fago A, Mathews AJ, Dewilde S, Moens L, Brittain T: The reactions of neuroglobin with $\mathrm{CO}$ : Evidence for two forms of the ferrous protein. $J$ Inorg Biochem 2006, 100:1339-1343.

39. Brunori M, Vallone B: Neuroglobin, seven years after. Cell Mol Life Sci 2007, 64:1259-1268

40. Fago A, Hundahl C, Dewilde S, Gilany K, Moens L, Weber RE: Allosteric regulation and temperature dependence of oxygen binding in human neuroglobin and cytoglobin. Molecular mechanisms and physiological significance. J Biol Chem 2004, 279:44417-44426.

41. Fraser J, de Mello LV, Ward D, Rees HH, Williams DR, Fang Y, et al: Hypoxiainducible myoglobin expression in nonmuscle tissues. Proc Natl Acad Sci USA 2006, 103:2977-2981.

42. Fordel E, Geuens E, Dewilde S, Rottiers P, Carmeliet P, Grooten J, et al:: Cytoglobin expression is upregulated in all tissues upon hypoxia: an in vitro and in vivo study by quantitative real-time PCR. Biochem Biophys Res Commun 2004, 319:342-348.

43. Schmidt M, Gerlach F, Avivi A, Laufs T, Wystub S, Simpson JC, et al:: Cytoglobin Is a Respiratory Protein in Connective Tissue and Neurons, Which Is Up-regulated by Hypoxia. J Biol Chem 2004, 279:8063-8069.

44. Roesner A, Hankeln T, Burmester T: Hypoxia induces a complex response of globin expression in zebrafish (Danio rerio). J Exp Biol 2006, 209:2129-2137.

45. Awenius C, Hankeln T, Burmester T: Neuroglobins from the zebrafish Danio rerio and the pufferfish Tetraodon nigroviridis. Biochem Biophys Res Commun 2001, 287:418-421.

46. Roesner A, Mitz SA, Hankeln T, Burmester T: Globins and hypoxia adaptation in the goldfish, Carassius auratus. FEBS J 2008, 275:3633-3643.

47. Gorr TA, Cahn JD, Yamagata H, Bunn HF: Hypoxia-induced synthesis of hemoglobin in the crustacean Daphnia magna is hypoxia-inducible factor-dependent. J Biol Chem 2004, 279:36038-36047.

48. Farazi TA, Waksman G, Gordon J: The biology and enzymology of protein N-myristoylation. J Biol Chem 2001, 276:39501-39504.

49. Leslie AGM: MOSFLM User Guide, Msoflm Version 6.2.3 Cambridge, UK: MRC Laboratory of Molecular Biology; 1993.

50. Evans PR: Proceedings of the CCP4 study weekend on data collection and processing UK: CLRC Daresbury Laboratory; 1993.

51. Terwilliger TC, Berendzen J: Automated MAD and MIR structure solution. Acta Crystallogr D Biol Crystallogr 1999, 55:849-861.

52. CCP4: Collaborative, Computational Project. CCP4; 1994.

53. Perrakis A, Morris R, Lamzin VS: Automated protein model building combined with iterative structure refinement. Nat Struct Biol 1999, 6:458-463.

54. Emsley P, Cowtan K: COOT: model-building tools for molecular graphics. Acta Crystallogr D Biol Crystallogr 2004, 60:2126-2132.

55. Murshudov GN, Vagin AA, Dodson EJ: Refinement of macromolecular structures by the maximum-likelihood method. Acta Crystallogr D Biol Crystallogr 1997, 53:240-255

56. Vagin A, Teplyakov A: MOLPREP: an automated program for molecular replacement. J Appl Crystallogr 1997, 30:1022-1025.

57. Laskowski RA: SURFNET: a program for visualizing molecular surfaces, cavities, and intermolecular interactions. J Mol Graph 1995, 13:323-328.

58. Berman HM, Westbrook J, Feng Z, Gilliland G, Bhat TN, Weissig H, et al.: The Protein Data Bank. Nucleic Acids Res 2000, 28:235-242.

59. Uzan J, Dewilde S, Burmester T, Hankeln T, Moens L, Hamdane D, et al:: Neuroglobin and other hexacoordinated hemoglobins show a weak temperature dependence of oxygen binding. Biophys J 2004, 87:1196-1204

60. Weber RE, Voelter W, Fago A, Echner H, Campanella E, Low PS: Modulation of red cell glycolysis: interactions between vertebrate hemoglobins and cytoplasmic domains of band 3 red cell membrane proteins. Am J Physiol Regul Integr Comp Physiol 2004, 287:R454-R464.

61. Hayashi A, Suzuki T, Shin M: An enzymic reduction system for metmyoglobin and methemoglobin, and its application to functional studies of oxygen carriers. Biochim Biophys Acta 1973, 310:309-316.

62. Hoogewijs D, Houthoofd K, Matthijssens F, Vandesompele J, Vanfleteren $J R$ : Selection and validation of a set of reliable reference genes for 
quantitative sod gene expression analysis in C. elegans. BMC Mol Biol 2008, 9:9.

63. Hellemans J, Mortier G, De Paepe A, Speleman F, Vandesompele J: qBase relative quantification framework and software for management and automated analysis of real-time quantitative PCR data. Genome Biol 2007, 8:R19.

64. Vandesompele J, De Preter K, Pattyn F, Poppe B, Van Roy N, De Paepe A, et al: Accurate normalization of real-time quantitative RT-PCR data by geometric averaging of multiple internal control genes. Genome Biol 2002, 3:research0034.1-0034.11.

65. Hobert O: PCR fusion-based approach to create reporter gene constructs for expression analysis in transgeni $c$ C. elegans. Biotechniques 2002, 82:728-730.

66. Kraulis PJ: MOLSCRIPT: a program to produce both detailed and schematic plots of protein structures. J Appl Crystallogr 2006, 24:946-950.

67. Olson JS, Philips GN: Myoglobin discriminates between oxygen, NO and $\mathrm{CO}$ by electrostatic ineteractions with the bound ligand. J Biol Inorg Chem 1997, 2:544-552.

68. De Baere I, Liu L, Moens L, Van Beeumen J, Gielens C, Richelle J, et al.: Polar zipper sequence in the high-affinity hemoglobin of Ascaris suum: amino acid sequence and structural interpretation. Proc Natl Acad Sci USA 1992, 89:4638-4642.

doi: 10.1186/1471-2091-11-17

Cite this article as: Geuens et al., Globin-like proteins in Caenorhabditis elegans: in vivo localization, ligand binding and structural properties BMC Biochemistry 2010, 11:17

Submit your next manuscript to BioMed Central and take full advantage of:

- Convenient online submission

- Thorough peer review

- No space constraints or color figure charges

- Immediate publication on acceptance

- Inclusion in PubMed, CAS, Scopus and Google Scholar

- Research which is freely available for redistribution 